Laboratorio de Arte, 7-1994 http://dx.doi.org/10.12795/LA.1994.i07.22

\title{
DOS NUEVAS APORTACIONES GRÁFICAS PARA EL ESTUDIO DE LA PARROQUIA SEVILLANA DE SAN MIGUEL
}

\author{
POR Álvaro PASTOR TORRES
}

La parroquia sevillana de San Miguel ', reedificada por orden de don Pedro el Justiciero tras el terremoto de 1356, y clausurada y derribaba por la Junta Revolucionaria surgida en Sevilla ras el estallido de "La Gloriosa" en septiembre de 1868, ocupaba la manzana delimitada hoy por la plaza del Duque y las calles Jesús del Gran Poder, Aponte y Trajano. Sobre su solar se alzó pocos años después el Teatro del Duque, obra del arquitecto Juan Talevera, sustituido en fechas no muy lejanas por el poco afortunado edificio de "los Sindicatos".

Hasta ahora, y si excluimos las vistas generales y planos históricos de Sevilla ${ }^{2}$, tan sólo res imágenes, un lienzo, una fotografía (ambas publicadas en la misma obra ${ }^{3}$ ) y un dibujo ${ }^{4}$, nos mostraban detalladamente otros tantos aspectos, dos interiores y uno exterior, de la parroquia de San Miguel, con el interés añadido

1. Para mayor información sobre este templo, GONZÁLEZ DE LEÓN, Félix: Noticia Artística de Sevilla. Sevilla, 1844. Vol. I, pp. 23-41 ; TASSARA Y GONZALEZ, José María: Apuntes para la Historia de la Revolución de Septiembre del año 1868, en la ciudad de Sevilla. Noticia de los templos y monumentos derribados y de las iglesias clausuradas, de orden de la Junta Revolucionaria. Sevilla, 1919, pp. 69-75 y ANGULO ÍN̄IGUEZ, Diego: Arquitectura mudéjar sevillana de los siglos XIII, XIV y XV. Sevilla, 1932, pp. 50-52.

2. CABRA LOREDO, María Dolores y SANTIAGo PÁEZ, Elena $M^{\mathrm{a}}$.: Iconografía de Sevilla. 1400-1650. Madrid, 1988, pp. $97-98$ ( $\mathrm{n}^{\circ} 36$ del catálogo, "Vista general de Sevilla", anónimo, 1585, $n^{\circ} 53$ San MIguel) y p. 103 ( $\mathrm{n}^{\circ} 37$ del cat., "Vista de Sevilla",ca. 1600, n 53 San MIguel). SERRERA, Juan Miguel y OLIVER, Alberto: Iconografía de Sevilla 1650-1790. Madrid, 1989, p. 156 ( $n^{\circ} 73$ del cat., "Plano de la ciudad de Sevilla", 1771, $n^{\circ} 29$... de San Miguel) y pp. 188-190 ( $\mathrm{n}^{\circ} 136$ del cat. "Vista general de Sevilla", 1726, $\mathrm{n}^{\circ} 8$ San Miguel).

3. TASSARA Y GONZÁLEZ, José María: $O p$. cir., pp. 68 bis y 72 bis. Recientemente estos documentos gráficos han sido reproducidos en ROS, Carlos et alii: Historia de la Iglesia de Sevilla. Sevilla, 1992, p. 675.

4. Obra de Gumersindo Díaz (1869) publicado por el profesor Sancho Corbacho en la reimpresión que prologó de GONZÁLEZ DE LEÓN, Félix: Noticia... Tomo I, Sevilla, 1973, p.208-d. También se reproduce en SANCHO CORBACHO, Antonio: Iconografía de Sevilla. Sevilla, 1975, lám. CXXII. 
de haber sido obtenidos tales documentos en el doloroso momento de su destrucción física ${ }^{5}$.

Francisco Peralta (1845-1896) ${ }^{6}$, pintor ecléctico y todavía bastante desconocido de la Sevilla del último tercio del siglo XIX, firmó y fechó ("Franc ${ }^{\circ}$ Peraltal 1868") el lienzo "Interior de San Miguel" (Lámina n' ${ }^{\circ}$ ) que se conserva en una colección particular sevillana. La nave central de la parroquia, ya vacía de todo mobiliario litúrgico y devocional, pero íntegra en su estructura arquitectónica, centra una composición en la que la luz entra oblicua desde la nave de la Epístola. Una persona vestida de oscuro y tocada con sombrero se apoya sobre el segundo pilar de la nave del Evangelio mientras anota o dibuja sobre una pequeña libreta. ¿Es acaso un autorretrato del pintor, o un contratista de derribos que controla al operario que agachado reúne los restos de madera esparcidos por el suelo? Sea cual fuere la respuesta lo cierto es que Peralta muestra a través de la escala humana la gran altura de las bóvedas del templo ${ }^{7}$.

La fotografía del ábside de San Miguel (Lámina no 2), publicada también en el libro de José María Tassara sobre los edificios destruidos en la Revolución de 1868, permitió al profesor Angulo hermanar esta cabecera con las de Omnium Sanctorum y San Esteban ${ }^{8}$. La instantánea debió tomarse desde los altos de una edificación de la calle Trajano a mediados de noviembre, una vez que hubo caído la torre, suceso que aconteció el día $12^{\circ}$. Al fondo destaca el mirador en construcción, de ahí los andamios, de la casa del Conde de Palomares que aquel año se estaba edificando bajo la dirección del maestro de obras Antonio de la Vega ${ }^{10}$.

5. El final jurídico de la parroquia, que desde 1899 se encontraba en la capilla de San Antonio Abab y había quedado convertida en filial de la de Santa María Magdalena, lo decretó el 1 de julio de 1960 el Cardenal Bueno Monreal (Boletín Oficial del Arzobispado de Sevilla, $n^{\circ} 1743$, p. 291). Desde 1868 hasta 1899 la parroquia y su jurisdicción pasó por las parroquias de San Lorenzo y San Vicente, la capilla del Museo y el colegio de San Gregorio.

6. VALDIVIESO GONZÁLEZ, Enrique: La pintura sevillana del siglo XIX. Sevilla, 1981, pp. 139-140. Del mismo autor: Historia de la pintura sevillana. Sevilla, 1986 pp. 455-456.

7. "magnífica, ancha y dilatada" son los calificativos dedicados a la nave mayor de San Miguel por GONZALEZ DE LEÓN, Félix: $O$ p. cit., p. 23.

8. ANGULO ÍNIIGUEZ, Diego: $O p$. cit., p. 51.

9. Véase a este respecto la carta de dimisión del canónigo Francisco Mateos Gago como vocal de la Comisión Provincial de Monumentos Históricos en la que da cuenta pormenorizada del proceso de destrucción de la parroquia de San Miguel en TASSARA Y GONZÁLEZ, José María: $\boldsymbol{O} \boldsymbol{p}$. cit., pp. 22-39. También el capítulo "La cuestión de los derribos" en MATEOS-GAGO Y FERNÁNDEZ, Francisco: Colección de opúsculos. Vol. I, tomo I, Sevilla, 1869, pp. 123-185.

10. SUÁREZ GARMENDIA, José Manuel: Arquitectura y urbanismo en la Sevilla del siglo XIX. Sevilla, 1986, pp. 235 y 336. 
La tercera representación gráfica conocida es el dibujo de Gumersindo Díaz " (Lámina $n^{\circ} 3$ ), fechado en $1869^{12}$, que se conserva en el Archivo de la Real Academia de Bellas Artes de Sevilla ${ }^{13}$. Con trazo muy sumario presenta ya una nave principal en alberca con dos apuntados perpiaños aún intactos y con abundantes escombros sobre la solería. El dibujo es muy preciso en la representación de los peculiares pilares ${ }^{14} \mathrm{y}$ las decoradas ménsulas. Una vez más, y en este caso sin elementos que puedan servir de escala, el sencillo dibujo nos muestra la suntuosidad y amplitud espacial de la fábrica gótica de San Miguel.

Hasta aquí lo ya concocido de San Miguel. Pasemos a examinar ahora pormenorizadamente las nuevas aportaciones gráficas que presentamos en este artículo.

\section{I.- ÁBSIDE DE LA PARROQUIA DE SAN MIGUEL.}

Durante el mes de marzo de 1994 ha estado expuesto en uno de los patios cubiertos del Ayuntamiento sevillano la última adquisición pictórica de importancia que ha llevado a cabo el cabildo de la ciudad: una aguada anónima de grandes proporciones $(105 \times 1.040 \mathrm{~cm}$.) que representa el cortejo del Santo Entierro "grande" de 1854. Expuesto para su venta en la central londinense de Sotheby's ${ }^{15}$ fue adquirido en 1992 por el anticuario sevillano don Antonio Plata del Pino, el cual a su vez lo enajenó al consistorio sevillano por cinco millones de pesetas ${ }^{16}$.

La existencia de esta interesante obra era ya conocida ${ }^{17}$, sobre todo a raiz de su reproducción en el Manifiesto de la Hermandad del Santo Entierro para la procesión magna del Sábado Santo de $1992{ }^{18}$. Las procesiones extraordinarias de la Hermandad del Santo Entierro, con una sucesión de "pasos" ordenados de acuerdo al desarrollo evangélico de la Pasión de Cristo, se iniciaron en 1850 por

11. Pintor ovetense formado en la sevillana Escuela de Bellas Artes bajo la tutela de Joaquín Domínguez Bécquer. Residió en Sevilla desde 1859 hasta su fallecimiento en 1894. Fue artista mediocre, más entusiasta que virtuoso, y cultivó con profusión el retrato. VALDIVIESO GONZÁLEZ, Enrique: Pintura..., pp. 135-136 e Historia..., pp. 452-453.

12. Por error tipográfico en la reimpresión de la Noticia Artística de González de León (vid. nota 4) el dibujo está fechado en 1860.

El derribo de San Miguel no se concluyó en su totalidad hasta bien entrado el año 1871 , SUÁREZ GARMENDIA, José Manuel: $O$ p. cit. p. 304.

13. Sección, Comisión de Monumentos. Dibujo sobre papel, $400 \times 270 \mathrm{~mm}$. De este autor se conservan en la Academia 51 dibujos, muchos de ellos aún inéditos.

14. "... ha sufrido grandes é importantes alteraciones, que han contribuido a desfigurarlo de todo punto. Tiene cortados los pilares, que debieron darle en otro tiempo más suntuosidad y gallardia." Descripción de San Miguel por AMADOR DE LOS RÍOS, José: Sevilla pintoresca. Sevilla, 1844, p. 309.

15. Sotheby's $14-\mathrm{II}-90, \mathrm{n}^{\circ} 183, \mathrm{p} .90$

16. $A B C$ de Sevilla, 18 de febrero de 1994, p. 47

17. CALVO SERRALLER, Francisco et alii: Iconografía de Sevilla. 1790-1868. Madrid, 1991, pp. 274-279.

18. CARRERO RODRÍGUEZ, Juan et alii: Manifiesto de la Hermandad del Santo Entierro. Magna Procesión de 1992. Sevilla, 1992, p.35. 
iniciativa del Ayuntamiento sevillano para honrar a los Duques de Montpensier, a la vez que para fomentar el turismo ${ }^{19}$. Ese año desfilaron el Viernes Santo, desde la plaza de la Magdalena hasta la Catedral, trece "pasos", diez de otras tantas hermandades, más los tres (Triunfo de la Santa Cruz, Urna y Duelo) del Santo Entierro.

La magna procesión de 1854 (Viernes Santo, 14 de abril), segunda en la Historia "semanasantera" sevillana, tuvo como punto de partida el entonces ya ex-convento de los Mínimos de San Francisco de Paula ${ }^{20}$, en la mediación de la calle Palmas ${ }^{21}$. En esta ocasión la nómina de "pasos" aumentó en dos, y por tanto, procesionaron quince. Con gran precisión y detallismo el autor anónimo de la aguada representa a lo largo de más de diez metros de pintura todo el cortejo. El orden de los pasos, precedidos éstos de varias parejas de nazarenos con cirios, canastillas y estandartes, coincide con el de la nómina oficial: Sagrado Decreto de la Trinidad, Sagrada Cena, Oración en el Huerto, Prendimiento, Sentencia de Pilatos, Columna y Azotes, Jesús del Gran Poder, Humildad y Paciencia, Expiración del Museo, Tres Necesidades, Descendimiento, Sagrada Mortaja, Triunfo de la Santa Cruz, Urna y Duelo.

Entre los "pasos" de las Tres Necesidades, vulgo La Carretería, y El Descendimiento (Quinta Angustia), décimo y undécimo respectivamente del cortejo, y justo detrás de un nutrido grupo de clérigos turiferarios tocados con bonetes y revestidos de casullas, se alza majestuoso el ábside de un templo (Lámina $\mathbf{n}^{\circ}$ 4). Aunque el ingenioso, y no siempre veraz autor de la aguada, nos muestra una cabecera de clara raigambre clasicista, con frontón triangular, apilastrados y óculos, su simple comparación con la fotografía conservada de San Miguel hace que podamos advertir claras similitudes entre ambos ábsides, y que sin duda el anómino autor, con ligeros apuntes del natural, idealizó posteriormente en su estudio. Así, suprimió la forma poligonal con contrafuertes para darle una continuidad semicircular, y las modestas edificaciones adosadas con posterioridad a su primitiva construcción (sacristía, cuarto de los ministros ${ }^{22}$ y testero de la capilla de la Soledad ${ }^{23}$ ) las convirtió en uno noble espacio más propio de la Italia renacentista que de la Sevilla de mediados del siglo XIX.

19. Sobre este tema, además del Manifiesto antes citado, puede consultarse CARRERO RODRÍGUEZ, Juan: Anales de las cofradías sevillanas. Sevilla, 1984, pp. 576-591. Del mismo autor: "El Santo Entierro de Sevilla" en $A B C$ de Sevilla, 5-8 de marzo de 1992. LEÓN MORGADO, José Joaquín: El Santo Entierro Grande. Sevilla, 1992, pp. 10-11.

20. Hoy iglesia del Sagrado Corazón de Jesús. Tras la desamortización este templo fue adquirido por la Sociedad Bíblica de Londrés para su conversión en iglesia protestante. Más tarde pasó a ser propiedad de Mr. John Sutherland quien lo cedió a la Compañía de Jesús. Más datos sobre este convento en GARCía GUTIERREZ, Pedro F. y MARTínEZ CARBAJO, Agustín F.: Iglesias de Sevilla. Madrid, 1994, pp. 308-314.

21. Desde el 15 de junio de 1900 Jesús del Gran Poder. MONTOTO DE SEDAS, Santiago: Las calles de Sevilla. Sevilla, 1940, p. 272.

22. Sobre la profunda reforma emprendida en la parroquia por el "Cura Vega" en 1827, véase GONZÁLEZ DE LEÓN, Félix: Op. cit. pp. 24-38.

23. Fue construida en 1827 en la cabecera de la nave del Evangelio. Sobre este particular, PASTOR TORRES, Álvaro: "La Soledad en la parroquia de San Miguel" en $A B C$ de Sevilla, 7 y 20 de diciembre de 1993, pp. 46 y 56. 
Aunque la arbitrariedad del autor para colocar edificios es grande, resultando por ello imposibles visiones de la Catedral y su entorno, algunos inmuebles cercanos al ábside de San Miguel quedan bien definidos en la pintura. Este es el caso de la Capitanía General, cuya puerta es custodiada por un soldado entre la centuria romana y el "paso" del Duelo. La residencia del Capitán General de Sevilla estuvo desde 1846 hasta 1880 en el número dos de la calle Palmas ${ }^{24}$, frente a la portada occidental de la parroquia de San Miguel.

Por tanto, la cercanía de los templos de San Miguel y San Francisco de Paula, por donde transcurrió el magno desfile, y la representación de varias edificaciones de la céntrica y burguesa collación dedicada al Arcángel victorioso refuerzan aún más esta teoría.

También la espadaña que se alza sobre el tejado de la nave del Evangelio nos confirma la hipótesis que venimos defendiendo. Una de las principales secuelas del terremoto de Lisboa sobre la fábrica de la parroquial de San Miguel fue la ruina de su torre ${ }^{25}$. Pedro de San Martín, maestro de obras que dirigió las labores de restauración, ordenó el derribo del segundo cuerpo de la misma ${ }^{26}$ y su sustitución "por un pequeño campanario para la esquila sobre los muros de la iglesia" 27

\section{II.- "INTERIOR DE UNA IGLESIA DURANTE UN SERMÓN".}

Con este genérico título se ha clasificado hasta ahora el lienzo de Francisco Cabral Bejarano (Lámina $n^{\circ}$ 5), que firmado y fechado en $1857^{28}$ se custodia en una colección particular hispalense. Ya el profesor Valdivieso anotó en su día que el tipo de elementos sustentantes sólo se correspondía en Sevilla con los de la parroquia trianera de Santa Ana, más el elenco de personajes que pululaban bajo las bóvedas góticas no se correspondían a los feligreses habituales por aquellos años de la popular y populosa "Catedral de Triana".

Desde el púlpito del Evangelio de la parroquial de San Miguel un desmotivado clérigo predica a una distinguida, burguesa y muy distraída concurrencia, ataviada con las mejores galas de los días de fiesta. Tonsurados pertigueros, galantes militares, recatadas señoras y animados caballeros platican junto a la reja del presbiterio que da paso a la capilla mayor, una de las más grandes y profundas de los templos medievales sevillanos.

24. VEGA VIGUERA, Enrique de la: La Capitanía General de Sevilla. Sevilla, 1984, pp. 155-165.

25. PASTOR TORRES, Álvaro: "El terremoto de Lisboa y sus consecuencias en la parroquia sevillana de San Miguel" en $A T R I O, \mathrm{n}^{\circ} 7$. Sevilla, 1994, en prensa.

26. Su estado primitivo antes del terremoto podemos verlo en el lienzo anónimo "Vista de Sevilla", realizado en 1726, y que se conserva en el Ayuntamiento de Sevilla. La torre de San Miguel está señalada con el número 8, SERRERA, Juan Miguel y OLIVER, Alberto: $O p$. cit., pp. 188-190 (nº 136 del catálogo).

27. Archivo General del Arzobispado de Sevilla (A.G.A.S.). Justicia, ordinarios, leg. 2644, "San MigueV Año de 1756/ Autos sobre la obra", fols. 2-3.

28. VALDIVIESO GONZÁLEZ, Enrique: Pintura sevillana..., p. 82. Historia de la..., p. 407. 
Este lienzo es compañero de otro interior de iglesia, en este caso durante una misa, también de Cabral Bejarano ${ }^{29}$. El ambiente personal de esta obra muestra también una distinguida concurrencia, con presencia de algún tipo más popular. El altar donde se está celebrando la Eucaristía, típico modelo dieciochesco de estípite, lo preside una Virgen gloriosa de candelero con Niño. Esta imagen mariana está flanqueada por sendas esculturas de la Virgen y San José, ambas acompañadas por el Niño Jesús. En el ático dos esculturas de santos, probablemente dominicos o trinitarios, enmarcan ún Calvario. Ni la descripción de este altar coincide con ninguno de los existentes en San Miguel, ni tampoco la bóveda de medio cañón con fajones que se abre en la parte superior del lienzo sobre la capilla mayor permite identificar el interior del templo con el de su "pendant".

Gracias al lienzo de Peralta, y a un inventario de la parroquia de San Miguel realizado por su párroco en febrero de $1834^{30}$, podemos afirmar hoy que el interior representado por Cabral Bejarano durante el sermón se corresponde con el de San Miguel. Además de las coincidencias en los pilares y demás elementos arquitectónicos, los "cuadros dentro del cuadro" que se reflejan en el lienzo, tratados con gran minuciosidad, coinciden con los que según el citado Inventario adornaban los pilares y muros de la céntrica parroquia que conoció a lo largo de su dilatada historia el bautizo de Daoíz, el casamiento de Diego Velázquez y los funerales de Francisco Pacheco y Rodrigo Caro.

En el primer pilar de la denominada "nave de la Soledad" (Evangelio) está colgado "un Santo Arzobispo sentado con un libro abierto", así descrito en el Inventario ${ }^{31}$, copia dieciochesca de los lienzos que Murillo pintó para la Sacristía Mayor de la Catedral por encargo del Arcediano de Carmona don Juan de Federigui. Hoy este cuadro se conserva en el despacho del mayordomo de la Hermandad de Jesús Nazareno, vulgo El Silencio ${ }^{32}$, en cuyo templo de San Antonio Abad estuvo la parroquia de San Miguel desde 1889 hasta 1960. Bajo él, un "Nacimt . como de tres cuartas con marco dorado".

En el segundo pilar, pintura e inventario vuelven a coincidir en un "Sto. Arzobispo con un cuchillo en la garganta, como de a bara y marco dorado".

Tampoco el tondo mariano pintado por Cabral Bejarano junto a la reja que guarda la entrada de una capilla, seguramente la de San José (desde 1841 de Nuestro Padre Jesús de la Pasión ${ }^{33}$ ), encierra sorpresa alguna. Es una tabla italiana

\section{Ibídem.}

30. A.G.A.S.: Justicia, ordinarios, leg. 82 : "San Miguel / Inventario de la Parroquia / Año de 1834". 31. Ibídem

32. GARCÍA DE LA CONCHA DELGADO, Federico: Estudio histórico-institucional de la Primitiva Hermandad de los Nazarenos de Sevilla (vulgo El Silencio). Sevilla, 1987, p.152.

33. En el muro del Evangelio de San Miguel, cuya nave presidía desde 1827 la capilla de la Soledad, y desde la cabecera hasta los pies del templo, se encontraban las capillas del Cristo del Amor y la Sagrada Entrada en Jerusalén (que arribaron allí en 1811 [1810 según González de León] desde el templo de Los Terceros), la de Jesús de Pasión (hasta 1841 titulada de San José, y anteriormente de Santa Catalina, donde reposaban los restos del erudito Rodrigo Caro), y tras la puerta que daba a la calle San Miguel (titulada Aponte en 1845), y bajo el hueco la torre, la capilla bautismal. 
del siglo XVI (c.1530), copia de un grabado de Rafael, que representa a la Virgen con el Niño y San Juanito ${ }^{34}$. Fue donada a la parroquial de San Miguel en 1761 por Doña María Ana Pérez de Garayo, hija de los condes de Lebrija y viuda del caballero de Calatrava don Ignacio Chacón y Salazar ${ }^{35}$. El tondo ya era ponderado por su calidad en los inventarios parroquiales del siglo XIX ${ }^{36}$. Gestoșo, que conoció el cuadro en San Antonio Abad, concretamente sobre la puerta de la sacristía, rechaza, aunque con reservas, la tradicional y ligera atribución de la obra al pintor de Urbino ${ }^{37}$. Hoy esta tabla preside el sotocoro de la capilla de San Antonio Abad ${ }^{38}$.

Aunque bajo esta célebre obra el inventario de 1834 coloca "un Ecce Homo sve. cobre también famosa pintura como de media bara" ${ }^{39}$, la pintura de Cabral Bejarano, fechada en 1857, parece presentarnos en ese lugar otro cuadro que también estaba inventariado en el muro del Evangelio de San Miguel, y que bien pudiera ser "los Desposorios", o "la Visitación de Sta. Isabel".

34. Catálogo-guía de la Exposición Mariana instalada en el templo del Divino Salvador. Sevilla, 1929, p. $12, n^{\circ} 29$. MORALES MARTíNEZ, Alfredo J. et alii: Guía artística de Sevilla y su provincia. Sevilla, 1981, pp. 129-130.

35. GESTOSO Y PÉREZ, José: Sevilla monumental y artística. Tomo III. Sevilla, 1892, p. 413-414.

36. Inventario de 1834 (vid. nota 22): "Un famoso ovalo en tabla que representa una Virgen con el Niño dormido svre. una sábana en el suelo, y un San Juan de rodillas inclinado svre. la Sra. figurando en el fondo o ambiente un paisaje que se dice con propiedad o tradición, ser original del célebre Rafael de Urbino, con un hermoso marco dorado".

37. GESTOSO Y PÉREZ, José: Op. cit., pp. 412-413.

38. GARCÍA DE LA CONCHA DELGADO, Federico: Op. cit., pp.153-154.

39. Obra de la escuela flamenca del siglo XVII que copia un original de Van Dyck. Tiene un valioso marco de bronce. El inventario de 1803 la situaba en el coro. Actualmente, bastante deteriorada, se encuentra en el despacho del mayordomo de la Hermandad del Silencio. GARCÍA DE LA CONCHA DELGADO, Federico: Op. cit. pp. 155-156. 


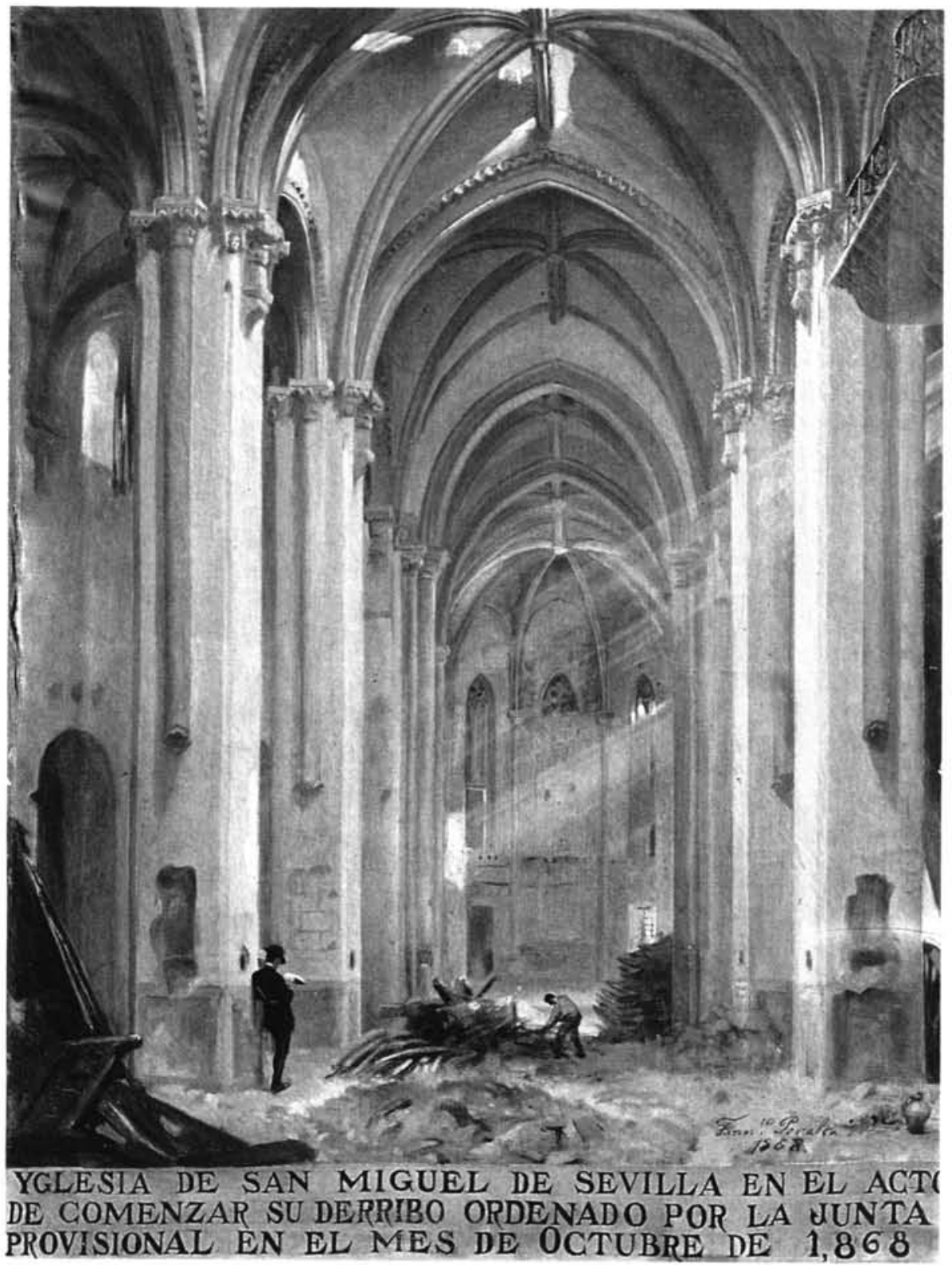

Lámina $n^{\circ} 1$ : Interior de la parroquia de San Miguel tras su clausura. Lienzo de Francisco Peralta. Sevilla, 1868. Colección particular, Sevilla. (Gentileza del profesor Valdivieso.) 


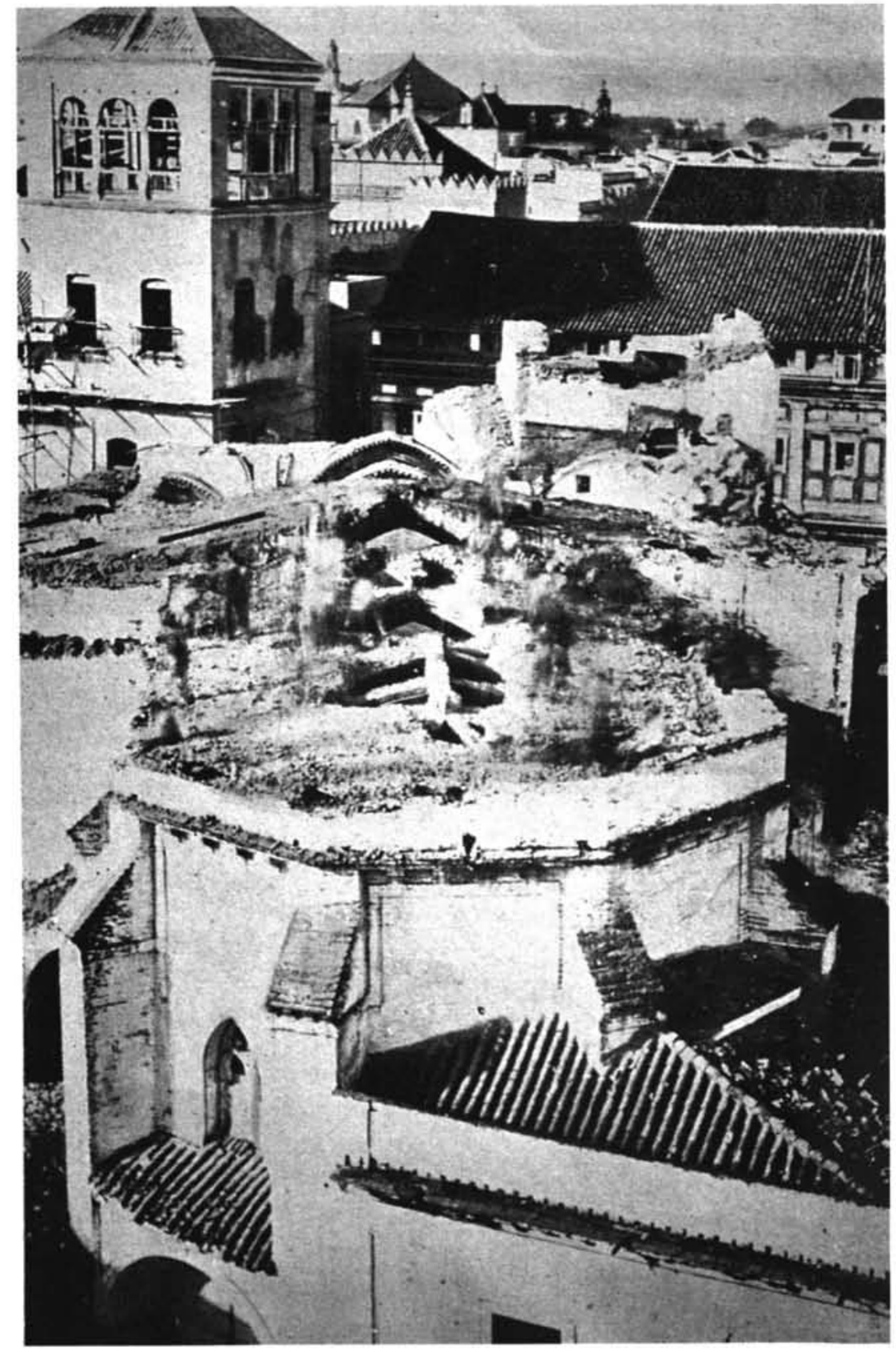

Lámina $n^{\circ}$ 2: Cabecera de la parroquia de San Miguel antes de su demolición. Noviembre de 1868. (Fotografía: Francisco M. Pérez Romero.) 


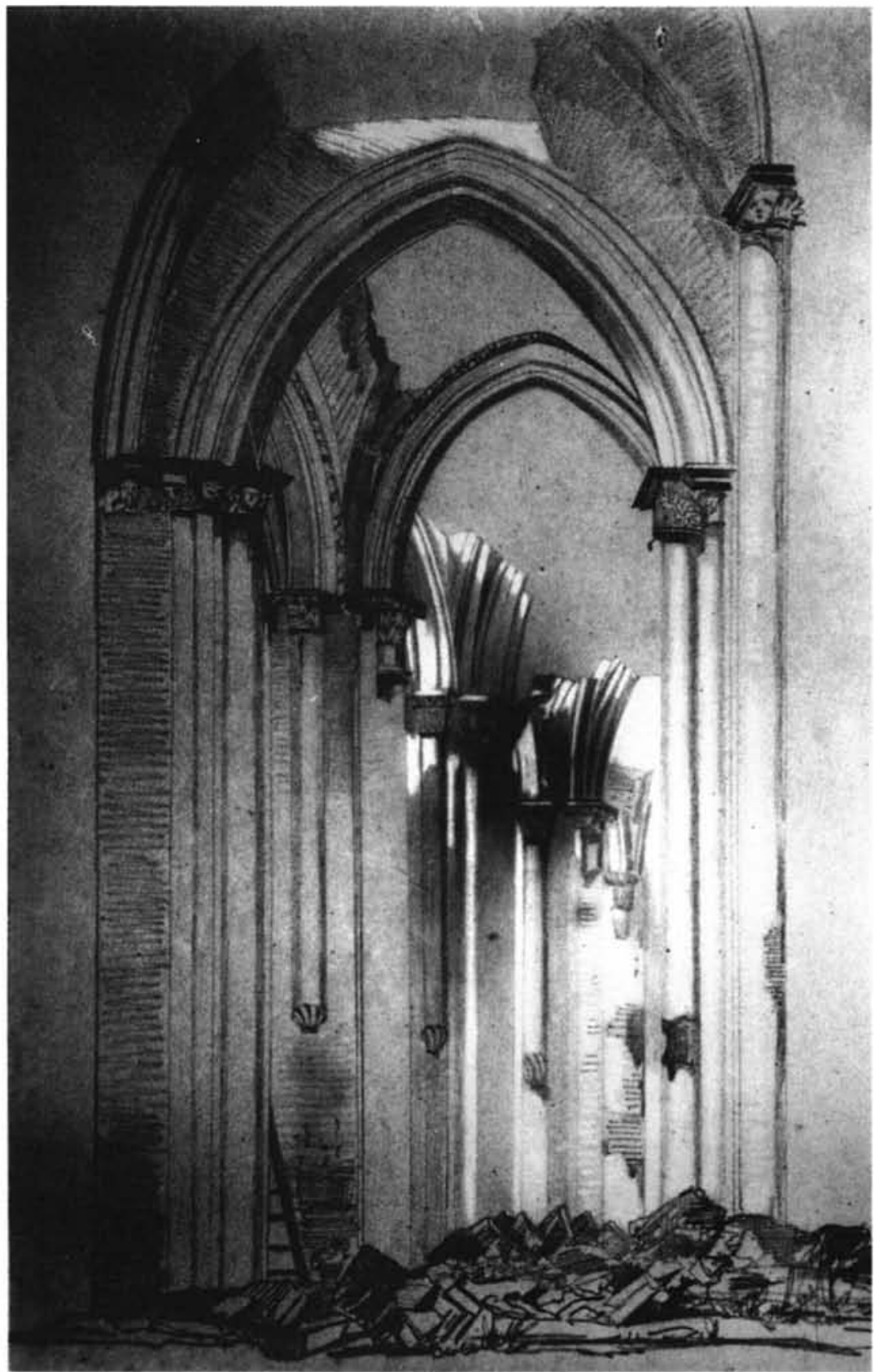

Lámina $n^{\circ}$ 3: Interior de San Miguel en ruinas. Dibujo de Gumersindo Díaz. Sevilla, 1869. Archivo de la Real Academia de Bellas Artes de Santa Isabel de Hungría de Sevilla. Sección, Comisión de Monumentos. Fototeca del Laboratorio de Arte. (Gentileza del profesor Suárez Garmendia.) 


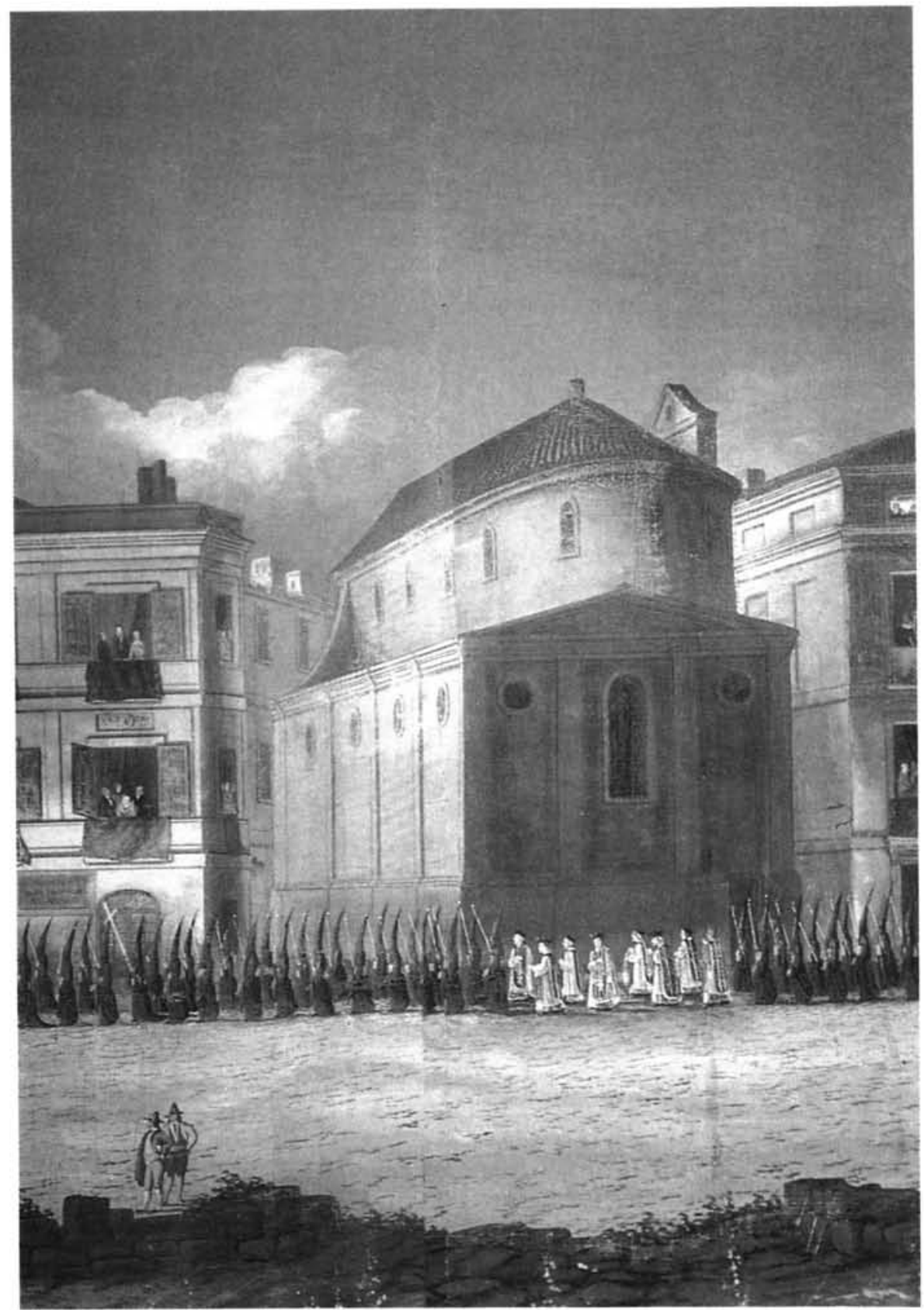

Lámina $n^{\circ} 4$ : Cabecera de la parroquia de San Miguel. Detalle de la procesión del Santo Entirro "grande" de 1854. Aguada anónima, c. 1854. Reales Alcázares de Sevilla. (Fotografía: Francisco M. Pérez Romero de la obra Iconografía de Sevilla. 1790-1868.) 


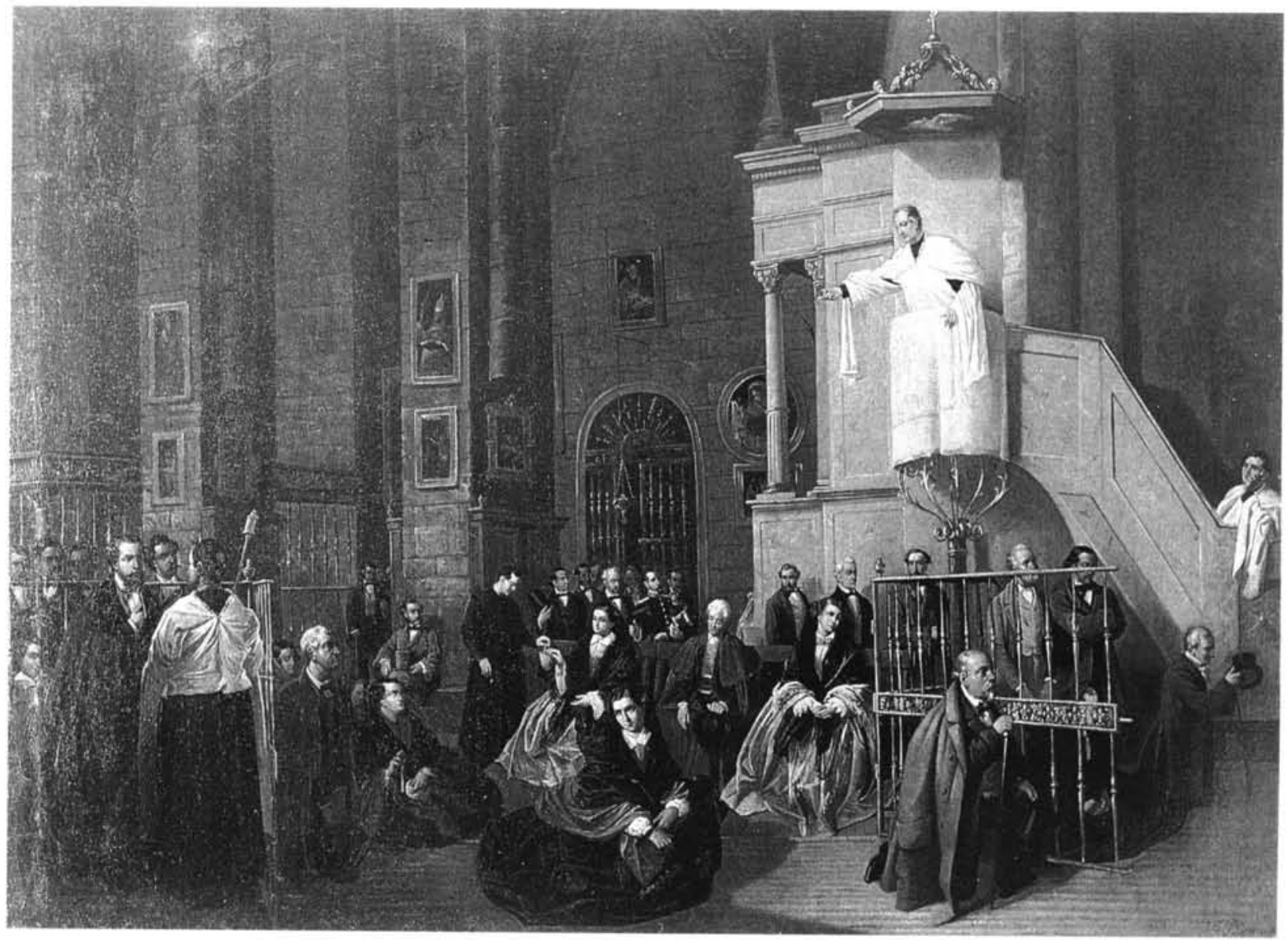

Lámina $\mathrm{n}^{\circ}$ 5: Interior de la parroquia de San Miguel durante un sermón. Lienzo de Francisco Cabral Bejarano. Sevilla, 1857. Colección particular, Sevilla. (Gentileza del profesor Valdivieso.) 